\title{
ТИПЫ ОБУЧЕНИЯ
}

\author{
П.С. Пробин
}

\section{Критерии и трудности оценивания студентов бакалавриата по непрофильным дисциплинам}

Аннотация. Объектом исследования в данной статье является оценивание студентов в высшей школе. Предмет исследования - критерии и трудности оиенивания бакалавров по непробильным дисииилинам. Особое внимание автора уделяется спеиибике непрофессиональных дисииплин как части образовательных программ бакалавриата и анализу оценивания студентов вузов в нынешней педагогической практике. Отдельно анализируется процесс оценки знаний по точным, гуманитарным наукам, а также по иностранному языку. Оиенивание студентов показано также в контексте мотивации студентов кучебе и их ориентированности на профессиональную деятельность.

Методом исследования является анализ существующей практики оценивания студентов в вузе, в том числе и на основе собственного опыта автора.

Основными выводами автора в данной статье являются следуюшие положения. 1) Особенности оценивания студентов зависят от специфики дисциплины. 2) Непрофильные дисциплины, не формируя напрямую профессиональных знаний умений и навыков, являются важной частью содержания подготовки бакалавров в контексте компетентностного подхода. 3) В современных условиях оценки студентов не отражают их реальных знаний и интеллектуального уровня и зачастую являются формальностью. Новизна статьи заключается в том, что проблемы оценивания в вузе отражены на основе классификации непрофильных дисииплин с учетом их специфики, а также сквозь призму мотивации студентов к учебе и будущей профессиональной деятельности.

Ключевье слова: оценивание, бакалавриат, непрофильные дисииплины, критерии, трудности, мотивация, высшее образование, оценки, иностранный язык, компетентностный подход.

Review. The object of research in this article is the assessment of students at higher school. The matter under study is the criteria and difficulties of assessing bachelors in non-professional disciplines. Particular author's attention is paid to specificity of non-professional disciplines as a constituent part of educational bachelor's programmes and to analysis of assessing students in present practice. Assessment in exact sciences and Humanities and foreign language are analyzed separately. Assessing students is also presented in the context of their motivation for learning and orientation to professional activity. The method of research in the article is the analysis of current practice of assessing students including the author's own experience. The main author's conclusions in this article involve the following statements. 1) Peculiarities of assessing students depend on the specificity of a discipline. 2) Even though they do not directly form professional knowledge and skills, non-professional disciplines are still an important constituent part of bachelor's curriculum in terms of the competence approach. 3) Nowadays school grades do not often reflect their actual knowledge and intellectual level and are a formality. The novelty of this article is in presenting problems of assessment at higher school on the basis of classification of disciplines and through the prism of students' motivation for studies and their orientation at their future professional activity.

Keywords: higher education, motivation, difficulties, criteria, non-professional disciplines, bachelor's course, assessment, grades, foreign language, competence approach. 


\section{Педагогика и просвещение 1(17) • 2015}

\section{Оценивание студентов по непрофильным дисциплинам как педагогическая проблема}

Согласно современным представлениям, в задачи высшей школы входит не только формирование у будущих специалистов профессиональных знаний, умений и навыков, но также и общих интеллектуальных качеств, эрудиции, расширение кругозора, воспитание социально значимых качеств личности, готовой кэффективному взаимодействию, как в профессиональной, так и в непрофессиональной деятельности. В рамках компетентностного подхода эти качества отражены в так называемых общих компетенциях, то есть тех, что не связаны непосредственно с профессиональной деятельностью будущего выпускника, но которые служат основой для его развития как профессионала, так и личности. Суть этих компетенций сводится к тому, что не зависимо от своей будущей профессии, современный специалист должен обладать определенными интеллектуальными и личностными качествами, дающими ему готовность работать в поликультурном обществе в эпоху развития телекоммуникационных технологий. Ему также необходимо иметь базовые представления о социально-гуманитарных и естественных науках, владеть иностранным языком, что позволит ему не только эффективно применять полученные знания, но и развиваться профессионально и личностно.

В рамках бакалавриата эти компетенции формируются в основном посредством общегуманитарных и естественнонаучных дисциплин, входящих в отдельные блоки и преподающихся, как правило, на младших курсах. К таким дисциплинам относятся философия, логика, история, социология, иностранный язык, экономика, математика и информатика, концепции современного естествознания и некоторые другие. Их набор варьируется в зависимости от конкретного направления подготовки, но их объединяет то, что они являются непрофильными.

Основная проблема преподавания таких дисциплин заключается в том, что они зачастую не интересны студентам, многие из которых уже с первого курса ориентированы на профессиональную деятельность. О.В. Флеров в своей статье отмечает, что очень часто они воспринимаются как формальность «для галочки» не только обучающимися, но и даже самими преподавателями, между тем они имеют, как уже было отмечено выше, существенное образовательное значение в высшей школе [1].

Одной из основных причин низкой мотивации студентов к изучению таких дисциплин является то, что они только что изучили основы этих наук в школе. Вряд ли университетские преподаватели в рамках коротких курсов могут изложить основы социально-гуманитарных и естественных наук на принципиально более высоком уровне, чем это делали педагоги в школе. Другое дело, что вузовский лектор может за счет нестандартного подхода, за счет неакадемического стиля попытаться привить студентам интерес к фундаментальным наукам, многие из которых считают науку весьма скучной вещью. Более подробно об этом рассказано в статьях Е.В. Волковой, Э.Р. Гатиатуллиной и Д.А. Гусева [2; 3; 4].

Проблемы оценивания студентов по таким дисциплинам органично вытекают из проблем их преподавания. Часто преподавателю просто не хочется «портить диплом» в будущем, возможно, классному специалисту плохой оценкой по непрофильному предмету, поэтому оценивание происходит слишком лояльно. Лояльное оценивание на первых курсах ведет в свою очередь к некой расслабленности, которая отрицательно влияет на освоение профильных дисциплин на старших курсах. Одной из самых больших проблем в этом смысле представляется система «скачал реферат (курсовую) и сдал зачет». Оценивание данных видов работ в эпоху Интернета следует существенно пересмотреть, и об этом тоже будет рассказано в данной статье.

Все дисциплины, с точки зрения критериев и особенностей оценивания, можно разделить на три совсем неравные группы. В одну войдет точная наука математика, являющаяся непрофильной для всех гуманитариев, другую составят социальногуманитарные, социально-экономические и естественнонаучные дисциплины, а в третью войдет иностранный язык. В данной статье мы вынесем за скобки обязательную дисциплину физкультуру, где зачет студентам ставится почти всегда за регулярное посещение занятий. Представляется, что это правильно, поскольку людям, не связавшим жизнь с профессиональным спортом нужно в первую очередь прививать тягу к здоровому образу жизни, к регулярным физическим упражнениям. Не следует «выжимать» из них какие-либо 


\section{Типы обучения}

нормативы, поскольку уровень физического развития у всех разный, но если человек любит спорт и регулярно занимается им, он как минимум будет здоров, а этого самое главное.

\section{Оценивание студентов бакалавриата по математике}

Для гуманитарных направлений непрофильной точной дисциплиной является математика и информатика. Особенностью математики как предмета в этом смысле является то, что задания, дающиеся студентам для контроля, подразумевают единственно верный ответ. Очевидно, при таком раскладе очень легко применить принцип объективности, который при любом оценивании является ведущим. Оценка напрямую зависит от количества правильно выполненных заданий. Оценивать студентов по математике с первого взгляда легко еще и потому, что у студента нет возможности оспорить оценку, ведь верным является единственный ответ. В вузовской практике знания по математике оцениваются таким способом как на контрольных, так и на зачетах и экзаменах. Здесь тем не менее возникают два существенных вопроса.

Первый заключается в том, какую планку должен ставить преподаватель для студентов, какое количество или какой процент верных ответов требовать. Получается, что даже в точных науках оценивание субъективно, если один за, скажем, три ошибки ставит пятерку, а другой - четверку. Кроме того следует ли на зачете ставить планку ниже, чем на экзамене? У многих студентов отношение к зачету такое, что раз он не предусматривает оценки, это лишь формальный контроль. На самом деле зачет - такая же форма контроля, как и экзамен, и недифференцированность оценки никак не должна подразумевать более низкие требования к подготовке.

Во-вторых, важным является принцип дифференцированности оценивания. Он подразумевает то, что следует оценивать не только ответ студента в конкретный момент, но и его прогресс, а также его волевые усилия. Например, если с точки зрения количества выполненных заданий студент на экзамене заслужил четверку, но при этом в начале курса он не мог сделать ни одного, представляется, что такой прогресс должен быть отмечен отличной оценкой. С другой стороны, применить такой принцип на практике можно только если преподаватель заранее оговорил, что те, кто будут хорошо заниматься (посещать занятия, выполнять все задания и т.д.) получат в итоге оценку на балл выше. Иначе это будет казаться несправедливостью.

Итак, мы видим, что даже при оценивании знаний по дисциплине, где студент может дать единственный верный ответ, есть место субъективности, что существенно осложняет процесс оценивания. Тем более сложнее оценить знания по дисциплинам гуманитарным, о чем пойдет речь в следующей части статьи.

\section{Оценивание студентов бакалавриата по гуманитарным, социально- экономическим и естественным дисциплинам}

В данную группу входят весьма разнородные учебные предметы: философия, социология, экономика, право, логика, концепции современного естествознания, экология, педагогика, психология и некоторые другие. Все их можно объединить благодаря тому, что ответ носит скорее устный, теоретический характер. Хотя практические задания тоже существуют, они часто не подразумевают единственно верного ответа, а требуют от студента именно понимания возможностей решить какую-либо проблему. Разумеется, в зависимости от того, как студент отвечает, проблема может быть более или менее раскрыта. Степень раскрытия проблемы, полноты ответа здесь выступают главным критерием оценки. Нельзя не отметить, что этот критерий весьма субъективен.

Проблема преподавания таких дисциплин заключается в том, что со школы о них формируется представление как об очень легких предметах, в которых в отличие от физики, математики и химии, где требуется что-то решать, достаточно только прочитать, выучить и ответить. Вообще принцип «сдал и забыл» очень серьезно понижает эффективность обучения в высшей школе в целом. У студентов с самого начала формируется ориентированность на репродуктивный ответ на зачете или экзамене, который надо выучить, и на этом с дисциплиной будет покончено.

В данном случае уместно вспомнить о традиционной билетной системе сдачи экзамена, которая обычно практикуется по рассматриваемым дисциплинам. В своей статье профессор Д.А. Гусев отмечает, что вместо того, чтобы требовать от сту- 


\section{Педагогика и просвещение 1(17) • 2015}

дента отвечать по одному билету, гораздо эффективнее было бы проводить блиц-собеседование по наиболее важному материалу всего курса. Если студент тянет один билет - это всегда лотерея. Оценивается глубина знания по двум-трем вопросам, в то время как задача преподавания подобных непрофильных предметов заключается именно в том, чтобы сформировать представления (пусть и не самые глубокие) о науке в целом [5]. Короткое собеседование исключает возможность списать ответы на заранее известные вопросы. Помимо этого вопросы по ходу позволяют понять, как студент мыслит вслух, что особенно ценно, поскольку оцениваться должно не только знание фактов, но и умение прийти к правильному ответу.

Следует также отметить, что степень полноты ответа не всегда можно объективно оценить по традиционной «пятибалльной шкале». Слово написано в кавычках, поскольку на самом деле она четырехбалльная, так как оценки «единица» официально не существует. Если учесть, что «два» - неудовлетворительная оценка, в диплом она идти не может, а по непрофильным предметам почти не ставится, то это означает, что реально существует только три оценки: «удовлетворительно», «хорошо» и «отлично». Если принять во внимание, что «удовлетворительно» часто ставится вместо «неудовлетворительно», то остается всего две оценки для тех, кто реально занимался. Воспринимается это современными студентами уже как должное. Понимая, что они получат «четыре»или «пять», почти все студенты претендуют исключительно на «отлично». Худший вариант - «четверку», многие из них воспринимают сегодня как неудачу и даже просят возможности ее пересдать. Получается парадоксальная ситуация: «хорошо» в глазах студентов означает «плохо».

Введение другой шкалы, например, десятибалльной вряд ли изменит ситуацию к лучшему, а скорее, наоборот, затруднит оценивание по гуманитарным дисциплинам. В этом случае, когда выбор оценок больше, преподавателю еще сложнее будет дать мотивированный ответ, почему студент получил, скажем, «шесть», а не «семь». В целом вузовские оценки очень сильно девальвировались за последние лет десять. Это связано в первую очередь с общим падением уровня образованности и понижением мотивации к учебе, часто в слабой группе педагог вынужден ставить отличные оценки «лучшим из худших». Такая си- туация невольно заставляет задуматься о том, что, возможно, оценки в высшей школе вообще стоит отменить, а ставить лишь зачеты. По крайней мере, с непрофильными дисциплинами возможно было бы провести такой эксперимент, поскольку напрямую оценки по ним о профессиональных навыках все же не говорят.

При набирающем популярность в последние годы дистанционном обучении, которое имеет некоторые преимущества и при определенных условиях может быть эффективным [6; 7], оценки по общегуманитарным и естественнонаучным дисциплинам «весят» меньше всего. Дело в том, что при отсутствии контроля со стороны преподавателя очень легко находить ответы на вопросы по таким предметам в Интернете, гораздо сложнее это сделать по дисциплинам общепрофессиональным и тем более узкоспециальным.

С появлением Интернета формальностьюдля многих стали рефераты и курсовые (и отчасти дипломные) работы. Иногда преподаватели, видя в который раз примерно один и тот же текст, даже не проверяют его и, поставив оценку «хорошо», сразу пускают сданную работу на черновики. Сейчас, когда чтобы получить информацию не нужно прилагать никаких усилий, достаточно сложно понять, по каким критериям следует оценивать данный вид заданий. Когда они были придуманы, оценивалось в первую очередь умение отыскивать нужную информацию в библиотеках и различных других источниках. Переписывая текст от руки, человек пропускает информацию через себя, тем самым запоминая ее. Сейчас научной информации в Интернете много, но та, которая в свободном доступе, в основном невысокого качества. Одни и те же тексты «плавают» по виртуальной сети и с минимальными модификациями сдаются в качестве рефератов, курсовых и дипломов. Причем иногда дело доходит до абсурда, когда, например, в библиографическое описание источника копируется цена книги.

Существует мнение, что эти виды заданий с появлением телекоммуникационных технологий себя изжили, и от них надо вообще отказаться. Предлагаются идеи требовать от студентов переработки текстов и доведения его до определенного процента оригинальности, однако, все равно это работа механического характера, и в любом случае пропускание через себя информации студентом не гарантирует ее понимание. Гораздо ценнее

DOI: 10.7256/2306-434X.2015.1.14592 


\section{Типы обучения}

представляется в этом смысле требование прописывать актуальность и концовку - заключение, в котором было бы некое результирующее знание.

Грамотно прописанная актуальность говорит о сознательности выбора темы, а также как минимум о понимании студентом сути проблемы. Результирующее знание - это нечто большее, чем просто выводы, которые обычно выписываются (а вернее копируются из текста) тезисно. Результирующее знание подразумевает обоснованное и аргументированное представление основной идеи реферируемой информации, это то новое, что студент узнал для себя в процессе написания работы.

Специфика гуманитарного знания делает его оценивание более сложным, чем в области точных наук. Еще сложнее оценить знания по дисциплине, которая сама по себе не является наукой вообще. Речь в данном случае идет об иностранном языке, который непрофильными студентами изучается вне контекста науки о нем - лингвистики.

\section{Оценивание студентов нелингвистического профиля по иностранному языку}

В наше время весьма много говорится и пишется о проблемах межкультурной и межъязыковой коммуникации [8; 9; 10; 11], а также о коммуникативной компетенции как об одной из ключевых для современного человека, равно как и о коммуникативном обучении иностранным языкам в данной связи $[12 ; 13 ; 14]$.

Сегодня владение языком - обязательное требование для кандидатов даже на невысокие должности в международные компании. Учитывая, что их сотрудники вынуждены иногда общаться с иностранцами больше, чем с соотечественниками, знания иностранного языка - существенная часть интеллектуального капитала организаций [15; 16]. Между тем, изучают иностранный язык в вузе все, а говорят хорошо на нем немногие, при этом у всех в дипломах стоят хорошие и отличные оценки. Из этого следует, что либо они сильно завышаются, либо оценивание происходит не по тем критериям.

Каковы критерии оценки знания языка? На этот вопрос можно ответить по-разному, смотря что именно мы оцениваем - лингвистические знания или речевые умения и навыки, а если последние - то в каком виде речевой деятельности. Под высоким уровнем владения иностранным языком можно понимать и беглую свободную речь, то есть отсутствие языкового барьера, и отсутствие в речи грамматических ошибок, и богатый словарный запас, и использование большого количества идиом и устойчивых выражений.

Если один человек свободно и комфортно общается с иностранцами, но при этом допускает ошибки в рамках школьной программы, а другой может читать серьезную литературу в оригинале без словаря, но при этом испытывает языковой барьер в реальной речи, оба могут заявлять о хорошем знании языка, однако, это будет очень разное по сути знание. Сложность оценивания студентов по языку заключается еще и в том, что это единственная дисциплина, где ошибки с точки зрения реальной практики не просто простительны, но и вполне естественны. Действительно, даже говоря на родном языке, мы совершаем ошибки, однако, понимаем друг друга. Слишком правильная грамматически речь, наоборот, выглядит неестественной и выдает в человеке иностранца [17].

Учитывая все это, преподаватели вузов идут чаще всего по самому легкому пути, оценивая только знания грамматики. Причем чаще всего для контроля знаний выбираются такие задания, где возможна единственная верная трактовка употребления того или иного языкового явления, иначе говоря - самые простые упражнения. Тем не менее, знание грамматики иностранного языка не означает знания самого языка и тем более не тождественно коммуникативной компетенции. Таким образом, существует противоречие между социальным заказом и оценкой знаний студентов. Для того чтобы оценивалась именно коммуникативная компетенция, нужно для начала, чтобы сами занятия в непрофильных вузах проходили в чисто коммуникативном ключе, для чего необходимо соблюдение ряда педагогических условий и переосмысление языковой подготовки нелингвистов в целом.

\section{Оценивание студентов бакалавриата в контексте их мотивации к учебе и профессиональной ориентированности}

Как оценки, получаемые студентами, влияют на их мотивацию к учебе? Насколько важно для современного молодого человека или девушки получить «отлично», а не «хорошо»? Для того чтобы ответить на эти вопросы, отметим следующие наблюдения, полученные в результате общения 


\section{Педагогика и просвещение 1(17) • 2015}

со студентами-бакалаврами, а также в результате наблюдения их общения между собой.

1) Нынешнюю молодежь отличает то, что все больше ее представителей уже с самого первого курса вынуждены работать. Особенно это касается тех, кто обучается на договорной основе. Современные социально-экономические реалии таковы, что все меньше родителей могут поддерживать детей материально хотя бы до старших курсов. Сегодня найти работу для студента не так тяжело, как может показаться, однако, найти работухотя бы средней квалификации, да еще и по своему направлению подготовки - очень сложно. Занимаясь неквалифицированной работой, студенты сильно устают даже не столько физически, сколько психологически, в результате чего многие уделяют учебе крайне мало времени. Проблемы занятости молодежи в современной России подробнее рассмотрены в статьях Е.А. Дробышева [18; 19]. Те молодые люди, которые смолоду достигают определенных успехов в работе, часто говорят, что им вообще все равно, какая будет оценка, лишь бы дисциплина была зачтена. На собственном опыте они с ранних лет понимают, что карьерный рост сегодня не зависит от вкладыша в дипломе и часто не зависит от диплома вообще, а следовательно, получить документ об образовании нужно «для галочки». У студентов, которые к двадцати годам накопили хотя бы какой-то профессиональный опыт шансы на хорошую работу после вуза значительно выше, хотя оценки у них могут быть хуже.

2) Большинство студентов придерживается мнения, что работодатели на оценки не смотрят, и что их вообще не интересует где и как ты учился, однако, когда доходит до экзамена, многие заявляют, что не рассчитывают меньше, чем на «отлично» даже при отсутствии должного уровня знаний.
Мой коллега О.В. Флеров рассказывал мне, что когда совмещал работу в вузе с корпоративным преподаванием английского языка, менеджеры по подбору персонала в крупных компаниях неоднократно говорили ему, что не смотрят на вкладыш в дипломе, поскольку считают, что нынешние оценки - это «фикция».

Таким образом, мы имеем замкнутый круг и «инфляцию» оценок и красных дипломов: чем больше студенты «бьются» за них, тем меньше работодатели это ценят. При этом сами студенты это понимают, но все равно оспаривают оценку «хорошо», руководствуясь принципом «а чем я хуже?». Представляется, что это некая ложная форма самоактуализации для молодых людей. Одна из функций оценивания - дать молодомучеловеку адекватное представление о достигнутом уровне с тем, чтобы он мог осознанно работать над своими недостатками. Очевидно, это сегодня не работает, и у современной молодежи формируется явно завышенное представление о собственных возможностях.

Таким образом, мы видим, что система оценивания студентов, сама по себе не лишенная недостатков, в наше время работает все меньше и меньше. Можно в принципе заменить ее на другую, но это вряд ли сработает. Это проблема не только дидактическая, но и психологическая. Студенты должны иметь мотивацию к получению знаний, к собственному развитию и к непрерывному образованию, оценки же - выступать производной величиной. Отсутствие должной мотивации в нынешних социально-экономических условиях - тема для отдельной статьи, но до тех пор, пока оценки не производная, а первообразная, представляется, что никакая система оценивания не будет эффективной.

\section{Список литературы:}

1. Флеров О.В. Особенности преподавания второго иностранного языка в нелингвистическом вузе // Современное образование. 2015. №1. С. 1-25.

2. Волкова Е.Г. Основные проблемы преподавания философии в вузе // Современное образование. 2015. №2. С. 80-115.

3. Гатиатуллина Э.Р. Горек ли корень учения? Или к вопросу о личности педагога в образовательном процессе // Современное образование. 2015. №2. С. 20-44.

4. Гусев Д.А. К вопросу о риторической культуре преподавателя высшей школы // Современное образование. 2015. №2. С. 141-176. 


\section{Типы обучения}

5. Гусев Д.А. Экзамен - всегда «праздник»? // Высшее образование в России. 2003. №2. С. 84-86.

6. Гусев Д.А. Основные принципы эффективного построения системы дистанционного обучения // Наука и школа. 2014. №5. С. 106-112.

7. Праводелов С.В. Преимущества дистанционного обучения и его виды // Современное образование. 2015. №2. С. 70-79.

8. Авсеенко Н.А. Теория и практика межкультурной коммуникации. М.: Макс-пресс, 2005. 208 с.

9. Грушевицкая Т.Г., Попков В.Д., Садохин А.П. Основы межкультурной коммуникации. М.: ЮНИТИДАНА, 2003. $352 \mathrm{c.}$

10. Персикова Т.Н. Межкультурная коммуникация и корпоративная культура. М.: Логос, 2006. 224 с.

11. Пивонова Н.Е. Кросскультурные коммуникации. СПб.: Знание, 2008. 66 с.

12. Китайгородская Г.А. Интенсивное обучение иностранным языкам. М.: Высшая школа, 2009. 280 с.

13. Пассов Е.И. Концепция коммуникативного иноязычного образования. СПб.: Златоуст, 2007. 200 с.

14. Флеров О.В. Повышение эффективности обучения студентов иностранному языку на основе коммуникативной методики: Автореф. дис. ... канд. пед. наук. М., 2013.

15. Рибокене Е.В., Алексашина Т.В. Поведенческие установки субъектов рынка интеллектуального капитала в условиях институциональной неоднородности // Транспортное дело России. 2013. №6. С. 74-75.

16. Флеров О.В. Корпоративное обучение английскому языку как способ повышения уровня коммуникативной компетенции сотрудников международных компаний // Современное образование. 2015. №2. С. 116-140.

17. Флеров О.В. Исправление ошибок в устной речи студентов в ходе коммуникативного обучения иностранным языкам // Высшее образование сегодня. 2012. №7. С. 63-65.

18. Дробышев Е.А. Проблемы трудоустройства молодежи в условиях современной России: теоретикоприкладной аспект // Социальная политика и социология. 2013. Т. 1. №2(92). С. 191-199.

19. Дробышев Е.А. Занятость молодежи: зарубежный опыт и его применение в России // Социальная политика и социология. 2012. №4(82). С. 285-293.

20. Ершова О.В. Историко-педагогический анализ эволюции контроля учебной деятельности // Высшее образование сегодня. 2013. №9. С. 51-53.

21. Ершова О.В. Концепты «мотивация» и «интерес» как средства повышения эффективности контроля учебной деятельности студентов вуза // Высшее образование сегодня. 2013. №8. С. 79-81.

22. Рыбакова Н.А. Феноменологические основы самоактуализации личности // Вестник Алтайской государственной педагогической академии. 2005. №5-2. С. 26-37.

23. Евсевичева И.В., Любимова Г.А. Самооценивание в профессиональной сфере // Психология и психотехника. 2011. №9. С. 49-59.

24. Богатырев С.Ю. Критерии эффективности руководства при подготовке выпускной квалификационной работы // Современное образование. 2013. №2. C. 115-133. (DOI: 10.7256/2409-8736.2013.2.9078. URL: http://www.e-notabene.ru/pp/article_9078.html).

\section{References (transliteration):}

1. Flerov O.V. Osobennosti prepodavaniya vtorogo inostrannogo yazyka v nelingvisticheskom vuze // Sovremennoe obrazovanie. 2015. №1. S. 1-25.

2. Volkova E.G. Osnovnye problemy prepodavaniya filosofii v vuze // Sovremennoe obrazovanie. 2015. №2. S. 80-115.

3. Gatiatullina E.R. Gorek li koren' ucheniya? Ili k voprosu o lichnosti pedagoga v obrazovatel'nom protsesse // Sovremennoe obrazovanie. 2015. №2. S. 20-44.

4. Gusev D.A. K voprosu o ritoricheskoi kul'ture prepodavatelya vysshei shkoly // Sovremennoe obrazovanie. 2015. №2. S. 141-176.

5. Gusev D.A. Ekzamen - vsegda «prazdnik»? // Vysshee obrazovanie v Rossii. 2003. №2. S. 84-86. 


\section{Педагогика и просвещение 1(17) • 2015}

6. Gusev D.A. Osnovnye printsipy effektivnogo postroeniya sistemy distantsionnogo obucheniya // Nauka i shkola. 2014. №5. S. 106-112.

7. Pravodelov S.V. Preimushchestva distantsionnogo obucheniya i ego vidy // Sovremennoe obrazovanie. 2015. №2. S. 70-79.

8. Avseenko N.A. Teoriya i praktika mezhkul'turnoi kommunikatsii. M.: Maks-press, 2005. $208 \mathrm{~s}$.

9. Grushevitskaya T.G., Popkov V.D., Sadokhin A.P. Osnovy mezhkul'turnoi kommunikatsii. M.: YuNITI-DANA, 2003. $352 \mathrm{~s}$.

10. Persikova T.N. Mezhkul'turnaya kommunikatsiya i korporativnaya kul'tura. M.: Logos, 2006. 224 s.

11. Pivonova N.E. Krosskul'turnye kommunikatsii. SPb.: Znanie, 2008. $66 \mathrm{s.}$

12. Kitaigorodskaya G.A. Intensivnoe obuchenie inostrannym yazykam. M.: Vysshaya shkola, 2009. $280 \mathrm{~s}$.

13. Passov E.I. Kontseptsiya kommunikativnogo inoyazychnogo obrazovaniya. SPb.: Zlatoust, 2007. 200 s.

14. Flerov O.V. Povyshenie effektivnosti obucheniya studentov inostrannomu yazyku na osnove kommunikativnoi metodiki: Avtoref. dis. ... kand. ped. nauk. M., 2013.

15. Ribokene E.V., Aleksashina T.V. Povedencheskie ustanovki sub"ektov rynka intellektual'nogo kapitala $\mathrm{v}$ usloviyakh institutsional'noi neodnorodnosti // Transportnoe delo Rossii. 2013. №6. S. 74-75.

16. Flerov O.V. Korporativnoe obuchenie angliiskomu yazyku kak sposob povysheniya urovnya kommunikativnoi kompetentsii sotrudnikov mezhdunarodnykh kompanii // Sovremennoe obrazovanie. 2015. №2. S. 116-140.

17. Flerov O.V. Ispravlenie oshibok v ustnoi rechi studentov $v$ khode kommunikativnogo obucheniya inostrannym yazykam // Vysshee obrazovanie segodnya. 2012. №7. S. 63-65.

18. Drobyshev E.A. Problemy trudoustroistva molodezhi v usloviyakh sovremennoi Rossii: teoretiko-prikladnoi aspekt // Sotsial'naya politika i sotsiologiya. 2013. T. 1. №2(92). S. 191-199.

19. Drobyshev E.A. Zanyatost' molodezhi: zarubezhnyi opyt i ego primenenie v Rossii // Sotsial'naya politika i sotsiologiya. 2012. №4(82). S. 285-293.

20. Ershova O.V. Istoriko-pedagogicheskii analiz evolyutsii kontrolya uchebnoi deyatel'nosti // Vysshee obrazovanie segodnya. 2013. №9. S. 51-53.

21. Ershova O.V. Kontsepty «motivatsiya» $\mathrm{i}$ «interes» kak sredstva povysheniya effektivnosti kontrolya uchebnoi deyatel'nosti studentov vuza // Vysshee obrazovanie segodnya. 2013. №8. S. 79-81.

22. Rybakova N.A. Fenomenologicheskie osnovy samoaktualizatsii lichnosti // Vestnik Altaiskoi gosudarstvennoi pedagogicheskoi akademii. 2005. №5-2. S. 26-37.

23. Evsevicheva I.V., Lyubimova G.A. Samootsenivanie v professional'noi sfere // Psikhologiya i psikhotekhnika. 2011. №9. S. 49-59.

24. Bogatyrev S.Yu. Kriterii effektivnosti rukovodstva pri podgotovke vypusknoi kvalifikatsionnoi raboty // Sovremennoe obrazovanie. 2013. №2. S. 115-133. (DOI: 10.7256/2409-8736.2013.2.9078. URL: http://www. e-notabene.ru/pp/article_9078.html). 